\title{
The First Step to Solving any Problem is Recognizing there is one!
}

\author{
Richard M. Fleming PhD, MD, JD ${ }^{1 *}$, Matthew R. Fleming в.s ${ }^{1}$, Tapan K. Chaudhuri $\mathrm{MD}^{2}$ \\ ${ }^{1}$ FHHI-OmnificImaging-Camelot, El Segundo, CA, United States \\ ${ }^{2}$ Eastern Virginia Medical School, Norfolk, VA, USA
}

^Corresponding author: Richard M. Fleming PhD, MD, JD, FHHI-OmnificImaging-Camelot, El Segundo, CA, United States; Email: rmfmd7@yahoo.com

Received: December 16, 2019; Accepted: January 09, 2020; Published: January 11, 2020;

\section{Short Communication}

Since the introduction of the Inflammation and Heart Disease Theory [1-3], a shift from a cholesterol only etiology for coronary artery disease (CAD) has occurred. Unfortunately, hundreds if not thousands of research studies - involving millions of dollars in vested funding - have focused on measuring changes in blood tests rather than measuring actual changes in CAD itself $[4,5]$.

The consequence has been an amalgam of misinformation fueled by opposing factions of scientists and pseudo-scientists resembling more of a schoolyard brawl than scientific search for the truth. From this brawl both the media and social scientific neophytes vie for attention - a demonstration of true social desperation and not scientific discourse.

Fundamental questions about the impact of diet and drug treatment [6-9] remain poorly addressed due to this deeply flawed approach - thus the role diet and lifestyle play in preventing CAD remain unanswered.

While we have some information about what may be happening to people [8] who change their diets - the truth is we do not know and we will not know until we decide to scientifically any the question by measuring [5-7] the changes in CAD, which diets and medications [9] have on people with and without underlying CAD. The first step to solving this question of dietary epidemiology and prevention of CAD is to recognize we haven't been measuring the problem - CAD - itself. The first step to solving any problem is recognizing there is one.

Acknowledgments: FMTVDM issued to first author. Figures expressly reproduced with permission of first author.

Figure 1. Coronary artery disease is an inflammatory process precipitated by more than a dozen variables. Each variable contributes to inflammation within the blood vessels of the body, including the coronary arteries to varying degrees in different individuals [1].

Figure 2. The $\mathrm{X}$-axis displays the composite blood profile including TC, fat, low HDL, IL-6, Lp, and Fib. The Y-axis displays changes in ischemia as measured by nuclear imaging. The standard regression analysis shows both the range of estimates (yellow) and the $95 \%$ confidence intervals (green). HDL, high-density lipoprotein; IL-6, interleukin-6; Lp-a, lipoprotein-a; Fib, fibrinogen; Tc, total cholesterol [4].

\section{References}

1. Fleming RM. Chapter 64. The Pathogenesis of Vascular Disease. Textbook of Angiology. John C. Chang Editor, Springer-Verlag New York, NY. 1999, pp. 787-798.

2. Fleming RM. Stop Inflammation Now! with Tom Monte. Published by Putnam Books and Avery Books. December 2003. ISBN: 0399151117

3. https://www.youtube.com/watch?v=Hvb_Ced7KyA\&t=22s

4. Fleming RM, Harrington GM. "What is the Relationship between Myocardial Perfusion Imaging and Coronary Artery Disease Risk Factors and Markers of Inflammation?" Angiology 2008;59:16-25.

5. The Fleming Method for Tissue and Vascular Differentiation and Metabolism (FMTVDM) using same state single or sequential quantification comparisons. Patent Number 9566037. Issued 02/14/2017.

6. Fleming RM, Fleming MR, McKusick A, Chaudhuri TK. The Diet Wars Challenge Study: Insulin Resistance, Cholesterol and Inflammation. ACTA Scientific Pharm Sci. 2019;3(6). ISSN: 2581-5423.

7. Fleming RM, Fleming MR, McKusick A, Ayoob KT, Chaudhuri TK. A Call for the Definitive Diet Study to End the Diet Debate Once and for All. Gen Med. 2019;7(1):322. DOI: 10.24105/2327-5146.7.322.

8. Fleming RM, Fleming MR, Chaudhuri TK, Harrington GM. Cardiovascular Outcomes of Diet Counseling. Edel J Biomed Res Rev. 2019;1(1):20-29.

9. Fleming RM, Fleming MR, Chaudhuri TK. How Beneficial are Statins and PCSK9-Inhibitors? Scho J Food \& Nutr 2019;2(3):213-218.DOI:10.32474/ SJFN.2019.02.000136.

Citation:

Richard M. Fleming, Matthew R. Fleming, Tapan K. Chaudhuri (2020) The First Step to Solving any Problem is Recognizing there is one!. Prev Med Epid Public Heal Volume 1(1): 1-3. 


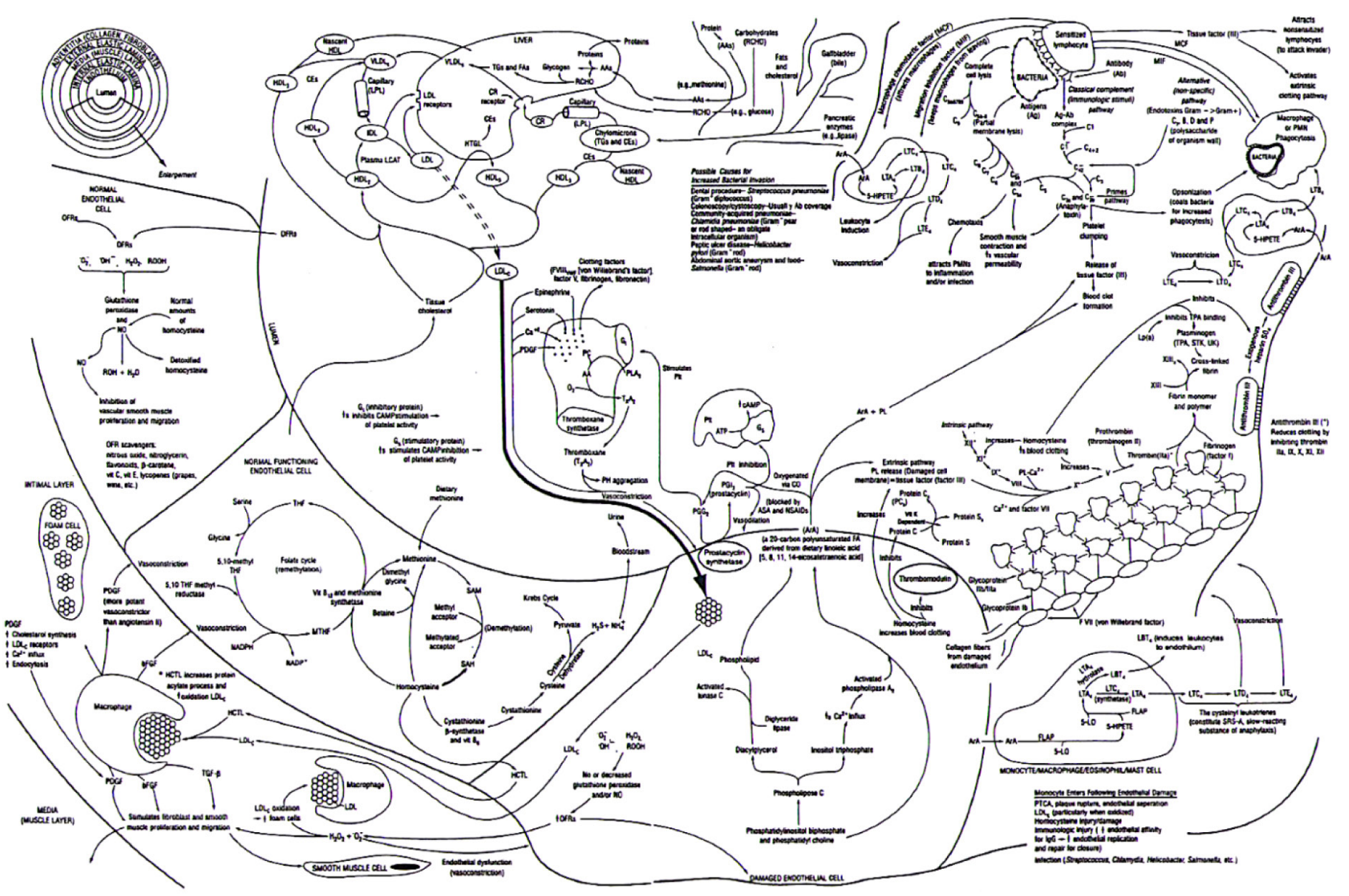

Figure 1. Fleming Inflammation and Vascular Disease Theory [2]. 


\section{Blood Flow Image Change vs Blood Chemistry Changes}

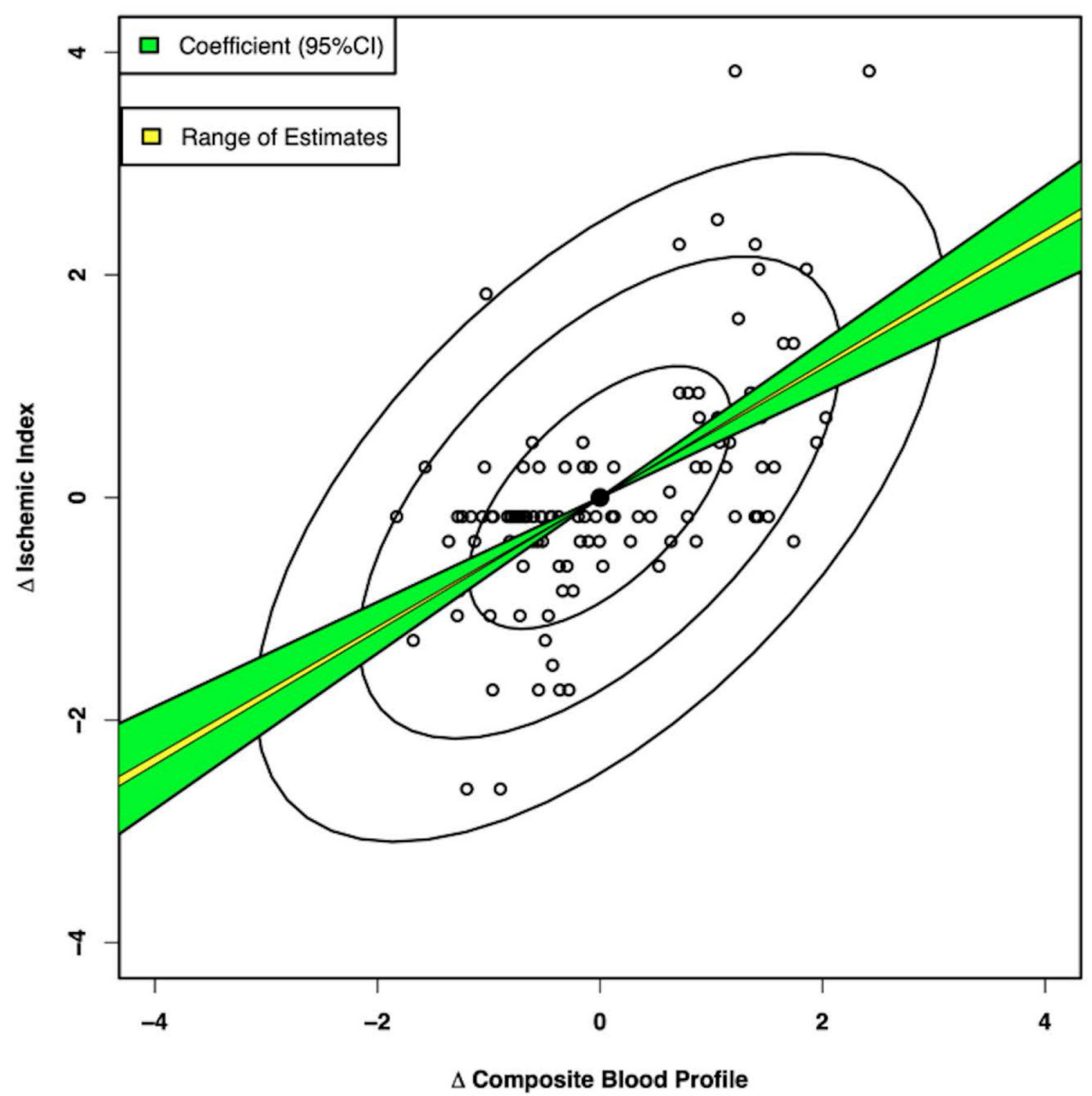

Figure 2. Standardized regression of coronary blood flow on composite blood profile [6]. 